\title{
Ten unsolved questions about neuroinflammation in Parkinson disease
}

Etienne C. Hirsch, $\mathrm{PhD}^{1}$ and David G. Standaert ${ }^{2}$

1 Faculté de Médecine de Sorbonne Université, Institut National de la Santé et de la Recherche Médicale, U 1127, CNRS, Unité Mixte de Recherche (UMR) 7225, Institut du Cerveau et de la Moelle épinière, ICM, Paris, France

2 Department of Neurology, University of Alabama at Birmingham, Birmingham, AL 35294, USA.

Word count: 4761 words (body of article only)

Running title: Unsolved questions on neuroinflammation in PD

Keywords: Lymphocytes, microglial cells, $\alpha$-synuclein, neurodegeneration,

The authors declare no link of interest related to the present article

Correspondance to

Etienne C. Hirsch

INSERM UMR 1127 - CNRS UMR 7225 - Université Pierre et Marie Curie, Institut du cerveau et de la moelle épinière - ICM, Thérapeutique Expérimentale de la Maladie de Parkinson, Hôpital de la Salpêtrière, Institut du Cerveau et de la moelle épinière, CS21414, 75646 PARIS CEDEX, France. Phone +33 157274557 Electronic address: etienne.hirsch@upmc.fr

Or

David G Standaert

Department of Neurology, University of Alabama at Birmingham, 1719 6th Ave. S, CIRC 520, Birmingham, AL 35294, USA. Phone +1 205-996-6233 Electronic address: dstandaert@uab.edu 


\section{Abstract}

Parkinson disease is a progressive and debilitating disorder which has so far eluded attempts to develop disease modifying treatment. Both epidemiological and genetic studies support a role of neuroinflammation in the pathophysiology of Parkinson disease. Post mortem studies and experimental analyses suggest the involvement of both innate as well as adaptive immunity in the degenerative process. There is also some circumstantial evidence for effects of immune therapies on the disease. In the present article, we review ten unanswered questions related to neuroinflammatory processes in Parkinson disease with the goal of stimulating research in the field and accelerating the clinical development of neuroprotective therapies based on antiinflammatory strategies. 


\section{Introduction}

Parkinson disease (PD) is a neurodegenenerative disorder classically characterized by a triad of motor symptoms: bradykinesia, rigidity and rest tremor. Recently, it has been recognized that the disease phenotype is in fact much broader. There are manifestations which precede these cardinal features and constitute the "premotor" symptoms of PD: constipation, bladder disorders, hyposmia, autonomic dysfunction, depression and sleep disorders. At the other extreme, in advanced disease patients suffer from poor balance, falls, cognitive impairment and dementia. (1) Pathologically, the symptoms of PD are accompanied by degenerative changes involving the brain, spinal cord, and peripheral nerves. There is profound depletion of dopaminergic neurons in the substantia nigra pars compacta (SNc), but also extensive degeneration of other structures including the locus ceruleus, hippocampus, and cortical structures. These changes are accompanied by the appearance of Lewy bodies, proteinaceous aggregates found in the SNc and other areas, and degenerating Lewy neurites which are often abundant in the hippocampus and cortex.

A major advance in the field was the discovery of the role of the protein $\alpha$-synuclein. Originally linked to the disease through genetic studies, it is now recognized as the core component of Lewy bodies and neurites. The use of immunohistochemical stains for $\alpha$-synuclein has revealed the extensive pathology present in PD. Early stages are associated with abnormal accumulation of $\alpha$-synuclein in enteric neurons of the gut, the vagus nerve, and other peripheral nerves. In the brain, the earliest changes are associated with $\alpha$-synuclein aggregates in the brainstem and olfactory bulb, with more advanced pathology appearing in the midbrain and eventually involving much of the cerebral cortex. (2) 
Over the last forty years a wide variety of hypotheses have been advanced to explain the cause of neuronal degeneration in PD. In the nineteen-eighties there were many studies of the role of oxidative stress, examining in particular dopamine auto-oxidation, neuromelanin formation, iron accumulation, reduced defense mechanisms against free radicals and mitochondrial dysfunction. (3) Excitotoxic mechanisms have also been explored, and there has been interest in environmental factors as well. At the beginning of the $21^{\text {th }}$ century, influenced by the discovery of $\alpha$ synuclein and its properties, the focus shifted to studies of protein misfolding and clearance. In this regard, reduced proteasome activity, deficient protein ubiquitination, mitophagy and intracellular organelle deficiencies have attracted much interest. (4) During the last ten years, the emphasis on protein misfolding has been further fueled by evidence that $\alpha$-synuclein has prion-like properties, and that misfolded $\alpha$-synuclein can seed further aggregation of endogenous protein and propagate from one cell to another, at least in experimental systems. (5)

This research on the mechanisms of PD degeneration (for review see 6) has allowed the identification of a myriad of potential targets for neuroprotection. However, all clinical trials of neuroprotection have failed so far. The lack of success with these strategies calls for a critical re-assessment of the underlying ideas and assumptions. While there many possible approaches to this, the authors believe that one of the core problems with current paradigms may be a misplaced emphasis on cellautonomous "neuronal" mechanisms in PD. Despite long-standing evidence for glial reaction in $\mathrm{PD}$, the role of non-cell autonomous mechanisms and neuroinflammation has only recently gained acceptance. (7) In this article, we summarize the data supporting a role of neuroinflammation in PD and highlight 10 unsolved questions regarding the role of immune responses in the pathogenesis of PD. 


\section{Evidence for neuroinflammation in PD}

In their seminal studies of post-mortem PD brain, McGeer and co-workers were the first to describe the presence of activated microglial cells and infiltrating lymphocytes in the substantia nigra. (8) As a whole, the field was slow to recognize the significance of this work. Nearly 20 years elapsed before there was a more detailed study demonstrating and quantifying the infiltration of T-lymphocytes (CD4 and CD8) but not of B-lymphocytes in the affected brain regions in PD. (9) Subsequent studies have confirmed that neuroinflammation is associated with the PD pathological process, with increased concentrations of pro-inflammatory cytokines in blood, CSF and even the brain postmortem of PD patients. (10) There are also changes in cellular immunity in the blood, with modifications in blood monocytes and T cells, including changes in Treg/Teff ratios and appearance of memory T cells with reactivity to specific epitopes of $\alpha$-synuclein. Evidence for brain inflammation in PD has also been obtained using neuroimaging approaches, primarily with ligands binding to TSPO. (11-13)

There have also been a number of studies which have demonstrated the importance of immune activation in animal models of PD. Neuroinflammation is observed across a broad range of PD model systems, including models based on neurotoxins such as 6-OHDA and MPTP and a variety of $\alpha$-synculein based models including transgenic animals, models based on viral delivery of a-synculein, and models induced by administration of misfolded $\alpha$-synuclein fibrils (for review see 7). Animal model systems allow studies of the causality of immune factors which is often difficult to assess directly in human PD, but of course these models need to be considered in the context of the authenticity with which they reproduce the disease mechanisms. 
Studies of neuroinflammation in PD are quickly gaining speed in the field, and promise to open the door to entirely new approaches to neuroprotective therapies. An important aspect of these approaches is that it is possible that a therapy for PD might be based on existing immunomodulatory treatments such as those which have been developed for multiple sclerosis and other inflammatory disorders, perhaps speeding delivery to clinical application. There are, however, a number of key issues which must be addressed in order to make progress towards immune-based neuroprotection in PD. Here, we review ten unanswered questions related to neuroinflammatory processes in PD with the goal of stimulating research in the field and promoting clinical development of neuroprotective treatments based on antiinflammatory strategies.

\section{Question 1: Does genetic variation in inflammatory genes contribute to the risk and progression of PD?}

Genome-wide association studies (GWAS's) suggest that neuroinflammation represents a risk factor for PD. Hamza and coworkers (14) first reported that common genetic variation in the HLA region is associated with risk for late-onset sporadic PD, a finding confirmed in an independent study. (15) Furthermore, Wissemann et al. (16) suggested that PD is associated with both structural and regulatory elements in the HLA region. In addition, they showed that noncoding SNPs in the HLA region can be associated with disease irrespective of HLA alleles, and that observed associations with HLA alleles can sometimes be secondary to a noncoding variant. Kannarkat et al. (17) extended this, showing that the non-coding SNP rs3129882 is associated with functional changes in $\mathrm{MHCll}$, including heightened baseline expression and inducibility of MHC class II molecules in B cells and monocytes. 
GWAS is a potent tool for identifying single-gene associations with disease, but pathway analysis reveals a much deeper and stronger genetic connection between PD and immune function. Holmans et al. analyzed in detail two large, independent GWAS data sets and found that the strongest associations were with two biological groups: the regulation of leukocyte/lymphocyte activity and cytokine-mediated signaling. (18) Zhang et al. used data from 3 independent GWAS studies and similarly found a strong association with variation in immune loci and PD risk, including the key immune regulatory HLA complex: HLA-DRA, HLA-DRB9, HLADRB1, HLA-DQA1, HLA-DRB9, and HLA-DPB2. (19) Gagliano et al. compared geneset enrichment in PD with MS, a classic immune-mediated disorder. (20) They found that both diseases exhibited enrichment of genes related to immune function. Interestingly, the sets of genes linked to PD were different from those in MS, suggesting different immunological processes at work in PD versus MS and thus the need for further study. Taking another track, Raj et al. studied expression quantitative trait loci (eQTL's) in monocytes from healthy control subjects, and found a marked over-representation of PD-related genes in monocyte populations. (21) Together, these data point to a strong link between the genetics of PD and modulation of immune function.

Nearly all of the genetic evidence linking inflammation and genetic variation is descriptive and based on associations. These type of studies cannot prove that neuroinflammation is causing PD. Further studies testing the role of each allele in animal models of the disease, and addressing the difficult challenges of modeling human immunity in another organism, are needed to determine their real implications in the pathological process. Another potential approach is examing the impact of genes which are unequivocally linked to forms of human PD, such as LRRK2, Parkin 
and PINK1, on immune functions (for review see 22). Studies addressing both approaches are needed to help understand how neuroinflammation represents a risk factor for the development and progression of PD.

\section{Question 2: Is it possible to analyze the evolution of neuroinflammation during the course of PD?}

So far, the strongest evidence for neuroinflammation in PD has been obtained from studies of risk factors or in postmortem studies. A key unmet need is a reliable approach to studing neuroinflammatory processes in living patients during the evolution of the disease. The main approaches which have been taken so far are studies of blood and CSF cytokines and chemokines, examination of cellular immunity in the blood, and brain imaging. While there has been some success with each of these approaches, an overall strategy for monitoring inflammation in living patients with PD is still lacking.

Qin et al. have recently reported a detailed review and meta-analysis of blood cytokines in PD. (23) Based on a systematic review of the literature, they pooled data from a total of 25 studies encompassing 2654 unique study participants, including 1547 patients with PD and 1107 healthy controls. They found clear evidence for elevation of several cytokines and chemokines in PD blood, including IL-6, TNF, IL$1 \beta, C R P, I L-2$ and RANTES. The main limitation identified, however, was that the studies included in general examined a mixed group of patients of varying disease durations and severity, and the published reports did not contain sufficient information about clinical state, disease duration, or concomitant therapy to disentangle these variables. The only large cohort study of blood cytokines and chemokines in early, incident PD is the recently reported ICICLE study. (24) In this 
series of 230 early PD cases and 90 controls, the authors found evidence for elevation of TNF, IL1-b, IL-2, and IL-10 in blood, and noted that pro-inflammatory phenotypes were associated with faster progression of clinical symptoms. CSF data were not available in this cohort. Indeed, in general data on CSF cytokines and chemokines are more limited, with most studies enrolling a broad range of disease durations and severities. (25-28) There is also the important question of whether blood and CSF inflammatory markers are correlated with each other, an area where there is little data.

Studies of changes in cellular immunity in PD are more limited. In a small patient cohort, Gardai et al. observed defects in phagocytosis in monocytes from PD patients (29), while Chahine et al found that PD patients with mutations in glucocerebrosidase, a strong genetic risk factor for PD, have elevated levels of monocyte-associated inflammatory markers in blood (30) More recently, Grozdanov et al. have described dysregulation of peripheral monocytes in PD, using cultured cells, flow cytometry and gene expression (31) They also found evidence of inflammatory activation, although the underlying patient population was very heterogeneous, with PD disease durations ranging from new onset to up to 20 years. Changes in circulating T cells have also been reported, including alterations in the ratios of Teff and Treg cells, a key regulator of inflammatory signaling. (32) Sulzer et al. have described the appearance of T cells with memory for $\alpha$-synculein epitopes, and have recently reported that these may appear even before the onset of motor symptoms, but whether these can used as a measure of disease activity is unknown. $(33,34)$

Positron emission tomography (PET) imaging analysis is another technique to analyze neuroinflammation in the brain. One of the first PET markers used to monitor 
neuroinflammation in vivo in the brain was [11C](R)-PK11195. (12) This tracer binds to a site originally identified as a "peripheral benzodiazepine receptor" and now recognized to be the Translocator Protein 18KD (TSPO), expressed in mitochondria and abundant in microglia and other macrophages. These authors reported an increased mean levels of [11C](R)-PK11195 binding in the pons, basal ganglia and frontal and temporal cortical regions in PD patients. Furthermore, the binding level remained stable two years apart. Yet, a few years later, Bartels et al. (35) performed a similar study and they concluded that "In current practice, [(11)C]-PK11195 seems an unsuitable tracer for accurate or reliable quantification of neuroinflammation". A new generation of TSPO tracers have recently been developed which offer greater sensitivity and reduced background. These include ${ }^{18} \mathrm{~F}$-DPA-714, and the related compound ${ }^{11} \mathrm{C}$-DPA-713. Terada et al. (13) recently reported imaging with ${ }^{11} \mathrm{C}$-DPA713 in a cohort of 11 early PD patients. These were mostly, although not exclusively, non-medicated early PD; some had durations of disease as long as 8 years. In this somewhat heterogeneous group, they found elevated uptake of ${ }^{11} \mathrm{C}-\mathrm{DPA}-713$ in both cortical and subcortical regions, and further increases in uptake with repeat scanning one year later. Ghadery et al. (36) noted that they could identify differences among genetic medium- and high-affinity TSPO binders, but not different between PD and control using ${ }^{18} \mathrm{~F}$-DPA-714 uptake in a small cohort with a wider range of disease durations.

Recently, Horti et al. (37) have developed ${ }^{11} \mathrm{C}-\mathrm{CPPC}\left[5-\mathrm{cyano}-\mathrm{N}-\left(4-\left(4-{ }^{11} \mathrm{C}-\right.\right.\right.$ methylpiperazin-1-yl)-2-(piperidin-1-yl)phenyl)furan-2-carboxamide], a positronemitting, high-affinity ligand that is specific for the macrophage colony-stimulating factor 1 receptor (CSF1R), the expression of which is essentially restricted to microglia within brain. It is highly and specifically taken up in the rodent and non- 
human primate brain indicating potential interest for human PET imaging of CSF1R and the microglial component of neuroinflammation. Increased binding to CSF1R has been described in Alzheimer disease, but so far has not been examined in PD. On the whole, none of these methods has so far yielded a reliable approach to monitoring PD-related inflammation in a living patient. This ability is critical for understanding the causal link between the progression of inflammation, neurodegeneration and $\alpha$-synuclein spreading (38) and is a key challenge for the field. Furthermore, in the future, it will be important to develop PET ligands for microglia/macrophages that can discriminate between the pro-inflammatory and the regulatory forms of these cells, as they have vastly different functions (see below). This is particularly important considering the possibility of treatments to modulate the phenotypes of these cells .

\section{Question 3: Is neuroinflammation in experimental models and the real disease different?}

One of the difficulties in linking the results obtained in human studies of PD and in experimental models of the disease arises from the differing character of immune response in different species. Differences likely arise from both the fundamental biological differences between species and the environment in which they are living. Striking differences in the responses of humans and mice to inflammation and injury are well documented. (39) In addition, most of the animal studies are performed in specific-pathogen-free (SFP) animal facilities while we are all in contact with pathogens during our whole life and even before birth. This might have a major consequence on the inflammatory status as immunogens might prime our immune system. Indeed, Carvey et al. (40) showed that prenatal exposure to the bacteriotoxin lipopolysaccharide (LPS) leads to long-term losses of dopamine neurons in offspring. 
Furthermore, this group also show that prenatal exposure to LPS exacerbates dopamine neuron degeneration induced by parkinsonian toxins. (30-42) One possible explanation for this increased susceptibility is that peripheral inflammation influences neuroinflammation. (43)

Another major difference between the clinical and the preclinical studies is related to gender, age and genetic background. Experimental studies are generally performed in males but inflammation is different in males and females; (44) studies are mostly performed in young animals and do not take into account immunosenescence which is different in PD and normal aging; (45) and studies are performed on inbred animals but genetic background influences the sensitivity to PD.

Behavioral factors might also affect the level and duration of neuroinflammation. Indeed, we have showed that chronic stress influences neuroinflammation via cortisol and glucorticoid receptors (GR) in the MPTP-mouse model of PD. (46) In this model, GR is important in curtailing microglial reactivity, and its deregulation in PD could lead to sustained inflammation-mediated DN injury.

Finally, most of the preclinical studies are performed in a single laboratory while clinical trials are multicentric. This calls for multicentric preclinical studies or replication studies.

Clearly, to reproduce the clinical situation, preclinical studies should be performed on males and females animals, grown in a stressful non-sterile environment and with mixed genetic background. Implementing such a strategy would require many more animals in each study, changes in the rules governing the animal facilities and much higher grant funding.

\section{Question 4: What triggers neuroinflammation in PD?}


If it is now well established that neurodegeneration is associated with neuroinflammation in PD but the trigger of neuroinflammation is still unknown. Many suspects are on the list but none of them are unambiguously guilty. Debris of degenerating neurons might represent an activating agent for microglial cells. As far as dopamine neurons are concerned, human neuromelanin induces neuroinflammation and neurodegeneration in the rat substantia nigra. (47) Yet, even before neurons disintegrate, affected neurons might activate microglial cells. Indeed, both in vitro and in vivo models of PD, degenerating neurons release heat shock protein (HSP 60) which acts throught TOLL like receptor 4 (TLR4) at the surface of the microglial cells to activate them. (48-49) Several groups of investigators have also shown that $\alpha$-synuclein activates microglia in experimental models of PD, (50, 51) but the precise structure of the immunogenic protein is still unclear. Posttranslational modifications of $\alpha$-synuclein may be important; indeed, nitrated $\alpha$ synuclein has been shown to be a potent stimulus and the response to this antigen is regulated by CD4+ T cell subsets. $(52,53)$ This concept is further supported by the fact that T cells from PD patients recognize specific a-synuclein epitopes. (33) Activation of alpha synuclein reactive $T$ cells might occur in the immune system at peripheral level because alpha synuclein has been detected in the cervical lymph nodes in an animal model of the disease. (54) Finally, the trigger for neuroinflammation in PD might come from outside of the nervous system. Supporting this hypothesis, Sampson et al., (55) using a highly controlled gnotobiotic system, showed that gut microbiota modify motor deficits and neuroinflammation in an experimental model of the disease, but one has to keep in mind that microbiome in human is highly variable in PD and has not yet been shown to be a disease trigger. 
What causes neuroinflammation in PD remains to be identified. Whether there is a single mechanism of immune activation or a combination of factors and whether it is a consequence of neuronal degeneration or even solely neuronal suffering remains the subject of great interest. What perpetuates neuroinflammation remains also a matter of debate. Misfolded alpha synuclein transiting from one neuron to another in a prion like mechanism might be at the origin of the self pertuation of neuroinflammation. This phenomenon might be exacerbated by the age-dependent defects of alpha-synuclein oligomer uptake in microglia and monocytes. (57) Alternately, a chronic elevated level of chemokines or their receptors located on lymphocytes, astrocytes or microglial cells might account for the chronicity of neuroinflammation in PD (58), perhaps driven by “inflammaging." (59)

\section{Question 5: What kind of cells are responsible for the innate immune response in PD? Angel or devil?}

The immune system is composed of two branches. Broadly speaking, innate immunity is driven by tissue resident macrophages, and provides the "first response" to antigen, while adaptive immunity is responsible for long-term memory responses. In the brain, microglial cells are the resident macrophages responsible for innate immunity. These are complex cells which have many different functions including neuromodulation, surveillance, sensing and phagocytosis. Whether these functions are shared by all microglial cells or are associated with specialized populations is not certain. (60) Furthermore, microglial cells can undergo activation and differentiation, classically described as "M1" pro-inflammatory and "M2" anti-inflammatory states, but recent work has revealed that there is in fact a spectrum of different activation states rather than a dichotomy. Futher complicating the analysis of microglia, it has been 
recognized in recent years that in addition to the brain microglia, there may also be macrophages present which have arisen from blood monocytes that can infiltrate the brain. Morphologically, these blood-derived macrophages can appear similar to the resident microglia, but they have different embryological origins and different properties. (60) In addition, border-associated macrophages have been described in the CNS but their roles (if any) has yet to be analyzed in PD. (61)

Several recent studies have attempted to better characterize the innate inflammatory response to PD. Parrilaud et al. analyzed the expression of the chemokines and their receptors in the substantia nigra pars compacta in an MPTP-treated mouse model. (58) They found that some of the chemokines are upregulated rapidly during the degenerative process, some of them late, and some of them even down regulated. This suggest that the inflammatory reaction is likely to change during the degenerative process. Using the chemokine receptor CCR2 as a marker, they observed blood monocytes which had infiltrated the brain during dopaminergic neurodegeneration. One must, however, acknowledge that the MPTP model of PD in rodents does not fully reproduces the chronicity of degeneration observed in humans or non-human primates. Indeed, while MPTP-induced microglial activation is transient in rodents $(62,63)$, it is chronic in non-human primates $(64)$ and humans (65). Similarly, Harms et al. (66) used an a-synuclein based model and showed not only infiltration of monocytes, but also that blocking this infiltration protected against the toxic effect of excess $\alpha$-synuclein. These observations suggest a cross talk between infiltrating monocytes and resident microglial cells, an example of "brainbody communication" in neurodegenerative disorders (discussed further below). This concept is further supported by the fact that when a systemic inflammatory event is combined with chronic neurodegeneration, primed microglia are further activated and 
damage endangered neurons, accelerating the pathology. (43) Blood-derived macrophages have not yet been directly observed in postmortem human PD brain, likely because current histological methods are not adequate to the task.

Altogether, these studies suggest that resident microglia and monocyte-derived macrophages may play multiple roles in PD. They may have neuroprotective roles in clearing misfolded $\alpha$-synuclein, the debris of degenerating cells and secreting antiinflammatory chemokines. Alternately, by secreting pro-inflammatory cytokines or activating the adaptive immunity via the chemokine network, they might exacerbate neuronal degeneration. Their functions might evolve during the course of the degenerative process depending of the cellular environment. Elucidating these roles remains a major challenge for understanding their role in neurodegenerative disorders.

\section{Question 6: Do lymphocytes play a role in PD pathogenesis?}

Lymphocytes also enter the brain parenchyma in PD and experimental models of the disease, indicating adaptive immunity is also important. Most studies of human brain have reported $T$ but not $B$ lymphocytes in PD; both CD4 and CD8 cells are present (for review see 7). The role of different types of $T$ cells in the disease process remains to be fully established. In the MPTP model, both CD4 and CD8 lymphocytes enter the brain but it appears that only CD4 cells participate in the degenerative process. (9) More recently, Sommer et al (67) have suggested that Th17 cells plays a specific role in the degenerative process. They observed a higher frequency of Th17 cells in the blood of PD patients and increased numbers of Th17 lymphocytes in postmortem PD brain tissues. Furthermore, using autologous co-cultures of activated T lymphocytes and iPSC-derived mid-brain neurons (MBNs) they showed that PD 
iPSC-derived MBNs underwent increased neuronal death in presence of T lymphocytes or the addition of IL-17. Altogether, this suggest a critical role for IL-17producing T lymphocytes in sporadic PD. Whether this is specific for Th17 lymphocytes or other lymphocytes also play a deleterious role remains to be established.

$\mathrm{MHClI}$, a protein genetically linked to risk for $\mathrm{PD}$, has the critical function of presenting peptide antigens on the surface of microglia for recognition by $T$ cells. Harms et al (51) have shown that microglial $\mathrm{MHCll}$ is required for the activation of both the innate and adaptive immune responses to $\alpha$-syn in PD and inducing of CD4 proliferation. This suggests a specific role of an a-synuclein related antigen in the engagement of adaptive immunity in PD. This hypothesis received recently a strong support with the discovery that T cells from the blood of patients with PD recognize $\alpha$ synuclein peptides. $(33,34)$

It is now clear that adaptive immunity also plays a role in neurodegeneration in PD. Yet, whether this is a consequence of other processes such a modification of $\alpha$ synuclein or other cellular components such as neurofilaments also detected in Lewy bodies remains to be determined. Whether subpopulations of lymphocytes participate in the clearing of $\alpha$-synuclein or exacerbate neuronal degeneration remains to be established. An answer to this question is crucial to determine how to counteract the deleterious effects of lymphocytes sub-populations in PD.

\section{Question 7: Are the brain-periphery interactions modified in the context of neuroinflammation in PD?}

The brain has been considered since the mid- $20^{\text {th }}$ century as a site of "immune privilege." This idea is now being challenged by new data on brain-body interactions 
under physiological conditions and in pathological states. In 2012, a new fluidclearance pathway known as the glymphatic (glial-lymphatic) pathway was identified in the rodent brain, and the key elements of this pathway also appear to be present in human brain (for review see 68). This system might be involved in PD on several levels as it allows for immune cells to enter the brain to conduct surveillance, and might allow misfolded proteins of brain origin to gain access to the periphery and stimulate neuroinflammatory processes. (69)

There are some clear examples of brain-periphery interaction in PD, including the evidence for lymphocyte (and likely monocyte) infiltration into the brain parenchyma (described above). The status of the blood brain barrier in PD remains to be determined. Kortekaas et al. (70) reported an opening of and/or transport changes across the BBB in PD but this has never been confirmed. More generally, this has raised the question of the status of brain microvascularization in PD. Two decades ago, increased neovascularization in PD patients and non-human primates models (but not rodents) was reported. $(71,72)$ This confirmed more recently $(73)$ but it appears that this is influences by both the degeneration of dopaminergic neurons as well as dopaminergic treatment (74). There may also be other pathways of brainbody communication in PD, including retrograde (and potentially anterograde) transport of proteins and signaling molecules through nerves such as the vagus, which provide for communication between the brain and peripheral organs. Elucidating these cellular, fluid and neuronal mechanisms of communication will be crucial to understanding the relationship of the brain to the periphery in PD.

\section{Question 8: When does inflammation begin in PD?}


It is well recognized that the onset of the motor symptoms of PD, such as tremor, occurs long after the onset of the disease process. While the details of the "premotor" phase of PD are still uncertain, most evidence suggests that this occupies a period of 10 years or more, during which there is progressive loss of dopaminergic function and appearance of non-motor symptoms such as autonomic impairment, hyposmia, and sleep disorders. This raises the corollary question of when inflammation begins in the course of PD. There is very little existing data on this point. Some investigators have begun to assemble cohorts of prodromal PD by screening high-risk populations. In line with this, Inflammatory biomarkers were recently examined in studies of $\operatorname{RBD}$ patients $(75,76)$ There is some circumstantial evidence from studies of blood cytokines which suggest that these are higher in early disease and decline with time, (77) as well as some evidence that blood lymphocytes recognizing $\alpha$-synculein antigens can be detected early. Stokholm et al. (78) have observed increased PK 11195 binding in subjects with RBD. On the whole, however, this is a critical question which requires further exploration.

\section{Question 9: Is there any existing evidence for a disease-modifying effect of immunotherapies in PD?}

Numerous epidemiological studies have used retrospective approaches to determine whether the use of anti-inflammatory drugs is associated with reduced risk of developing PD. Most of these studies have examined the commonly used nonsteroidal anti-inflammatory drugs (NSAID's). Gao and co-workers first reported that the intake of non-aspirin NSAID's reduced the risk of developing PD and later that this effect was largely explain by ibuprofen. (79) These results have proved controversial, with replication in some larger meta-analyses, but not in others. (80-82) 
Similarly, minocycline, an inhibitor of microglial activation, did not appear promising in a phase 2 "futility" clinical study in PD, (83) but this does not exclude a positive effect in a more thorough study. A more convincing case can be made for treatments that target tumor necrosis factor alpha (TNFa). Considerable preclinical work has shown that this inflammatory mediator is important in PD model systems. In a large retrospective study using the Medicare database, Peter et al. (84) found that inflammatory bowel disease (IBD) increased risk for the development of PD, a result expected because PD and IBD share genetic links, including LRRK2. Surprisingly, however, patients treated for IBD using anti-TNFa medications had a drastic reduction in PD risk, with nearly a 90\% reduction in PD in those who had received treatment.

All of these data are of course retrospective and associational; they cannot establish causality between immune treatments and reduced risk of PD. The next steps are likely prospective studies, and ultimately randomized, double-blind studies will be needed to fully assess the effects of immunomodulation in PD.

\section{Question 10: What is the future of anti-inflammatory interventions in PD?}

Interest in the role of the immune system in PD is growing rapidly. In 2002 there were less than 50 papers published on PD and inflammation, while in 2019 there were more than 700 . Studies of neuro-inflammation are likely to help the field bring together disparate ideas about the cause of PD: there may be multiple factors which trigger PD, both genetic and environment, but inflammation may represent a common pathway by which the disease progresses. If this idea is correct, immunomodulatory treatments may prove valuable across the whole spectrum of PD, from pre-motor to more advanced stages. 
A critical issue for therapeutics is identifying the most appropriate targets. It should be clear at this point is that there is a range of possibilities encompassing a variety of cellular and molecular mechanisms. There is also the question of therapeutic delivery; given the evidence for participation of circulating immune mechanisms, it is conceivable that a treatment targeting peripheral cells or their ability to enter the CNS might be effective (85).

Through these questions, we have tried to define some of the key open questions in the field and to stimulate further study. It is our hope that these ideas will accelerate progress towards a vision expressed by James Parkinson himself in 1817: "There appears to be sufficient reason for hoping that some remedial process may ere long be discovered, by which, at least, the progress of the disease may be stopped." (86) 


\section{References}

1. Hawkes $\mathrm{CH}$, Del Tredici $\mathrm{K}$, Braak H. A timeline for Parkinson's disease. Parkinsonism Relat Disord. 2010;16(2):79-84.

2. Braak H, Del Tredici K, Rüb U, de Vos RA, Jansen Steur EN, Braak E. Staging of brain pathology related to sporadic Parkinson's disease. Neurobiol Aging 2003; 24: 197-211.

3. Hirsch EC. Why are nigral catecholaminergic neurons more vulnerable than other cells in Parkinson's disease? Ann Neurol. 1992;32 Suppl:S88-93

4. Obeso JA, Rodriguez-Oroz MC, Goetz CG, Marin C, Kordower JH, Rodriguez M, Hirsch EC, Farrer M, Schapira AH, Halliday G. Missing pieces in the Parkinson's disease puzzle. Nat Med. 2010; 16:653-61.

5. Volpicelli-Daley L, Brundin P. Prion-like propagation of pathology in Parkinson disease. Handb Clin Neurol. 2018;153:321-335.

6. Michel PP, Hirsch EC, Hunot S. Understanding Dopaminergic Cell Death Pathways in Parkinson Disease. Neuron. 2016 May 18;90(4):675-91

7. Hirsch EC, Hunot S. Neuroinflammation in Parkinson's disease: a target for neuroprotection? Lancet Neurol. 2009; 8:382-97.

8. McGeer PL1, Itagaki S, Boyes BE, McGeer EG. Reactive microglia are positive for HLA-DR in the substantia nigra of Parkinson's and Alzheimer's disease brains. Neurology. 1988 Aug;38(8):1285-91. 
9. Brochard V, Combadière $B$, Prigent $A$, et al. Brain infiltration of CD4 lymphocytes contributes to neurodegeneration in Parkinson's disease model. J Clin Invest 2008; 119:182-92.

10. Nagatsu T, Mogi M, Ichinose $H$, Togari A. Changes in cytokines and neurotrophins in Parkinson's disease. J Neural Trans 2000(60):277-290.

11. Ouchi Y, Yoshikawa E, Sekine Y, Futatsubashi M, Kanno T, Ogusu T, Torizuka T. Microglial activation and dopamine terminal loss in early Parkinson's disease. Ann Neurol. 2005 Feb;57(2):168-75.

12. Gerhard A, Pavese N, Hotton G, Turkheimer F, Es M, Hammers A, Eggert K, Oertel W, Banati RB, Brooks DJ. In vivo imaging of microglial activation with [11C](R)-PK11195 PET in idiopathic Parkinson's disease. Neurobiol Dis. 2006 Feb;21(2):404-12

13.

14. Terada T, Yokokura M, Yoshikawa E, Futatsubashi M, Kono S, Konishi T, Miyajima H, Hashizume T, Ouchi Y. Extrastriatal spreading of microglial activation in Parkinson's disease: a positron emission tomography study. Ann Nucl Med. 2016 Oct;30(8):579-87.Hamza TH, Zabetian CP, Tenesa A, Laederach A, Montimurro J, Yearout D, Kay DM, Doheny KF, Paschall J, Pugh E, Kusel VI, Collura R, Roberts J, Griffith A, Samii A, Scott WK, Nutt J, Factor $\mathrm{SA}$, Payami $\mathrm{H}$. Common genetic variation in the HLA region is associated with late-onset sporadic Parkinson's disease. Nat Genet. 2010; 42:781-5.

15. International Parkinson Disease Genomics Consortium, Nalls MA, Plagnol V, Hernandez DG, Sharma M, Sheerin UM, Saad M, Simón-Sánchez J, Schulte C, 
Lesage S, Sveinbjörnsdóttir S, Stefánsson K, Martinez M, Hardy J, Heutink P, Brice A, Gasser T, Singleton AB, Wood NW. Imputation of sequence variants for identification of genetic risks for Parkinson's disease: a meta-analysis of genome-wide association studies. Lancet. 2011; 377:641-9. Wilms H, Rosenstiel P, Sievers J, Deuschl G, Zecca L, Lucius R. Activation of microglia by human neuromelanin is NF-kappaB dependent and involves p38 mitogen-activated protein kinase: implications for Parkinson's disease. FASEB J. 2003; 17:500-2.

16. Wissemann WT, Hill-Burns EM, Zabetian CP, Factor SA, Patsopoulos N, Hoglund B, Holcomb C, Donahue RJ, Thomson G, Erlich H, Payami H. Association of Parkinson disease with structural and regulatory variants in the HLA region. Am J Hum Genet. 2013; 93(5):984-93

17. Kannarkat GT, Cook DA, Lee JK, Chang J, Chung J, Sandy E, Paul KC, Ritz B, Bronstein J, Factor SA, Boss JM, Tansey MG. Common Genetic Variant Association with Altered HLA Expression, Synergy with Pyrethroid Exposure, and Risk for Parkinson's Disease: An Observational and Case-Control Study. NPJ Parkinsons Dis. 2015;1. pii: 15002.

18. Holmans P, Moskvina V, Jones L, Sharma M; International Parkinson's Disease Genomics Consortium, Vedernikov A, Buchel F, Saad M, Bras JM, Bettella F, Nicolaou N, Simón-Sánchez J, Mittag F, Gibbs JR, Schulte C, Durr A, Guerreiro R, Hernandez D, Brice A, Stefánsson H, Majamaa K, Gasser T, Heutink P, Wood NW, Martinez M, Singleton AB, Nalls MA, Hardy J, Morris HR, Williams NM. A pathway-based analysis provides additional support for an immunerelated genetic susceptibility to Parkinson's disease. Hum Mol Genet. 2013 Mar 1;22(5):1039-49. 
19.Zhang M, Mu H, Shang Z, Kang K, Lv H, Duan L, Li J, Chen X, Teng Y, Jiang Y, Zhang R. Genome-wide pathway-based association analysis identifies risk pathways associated with Parkinson's disease. Neuroscience. 2017 Jan 6;340:398-410.

20. Gagliano SA, Pouget JG, Hardy J, Knight J, Barnes MR, Ryten M, Weale ME. Genomics implicates adaptive and innate immunity in Alzheimer's and Parkinson's diseases. Ann Clin Transl Neurol. 2016 Nov 4;3(12):924-933.

21. Raj T, Rothamel K, Mostafavi S, Ye C, Lee MN, Replogle JM, Feng T, Lee M, Asinovski N, Frohlich I, Imboywa S, Von Korff A, Okada Y, Patsopoulos NA, Davis S, McCabe C, Paik HI, Srivastava GP, Raychaudhuri S, Hafler DA, Koller D, Regev A, Hacohen N, Mathis D, Benoist C, Stranger BE, De Jager PL. Polarization of the effects of autoimmune and neurodegenerative risk alleles in leukocytes. Science. 2014 May 2;344(6183):519-23.

22. Johnson ME, Stecher B, Labrie V, Brundin L, Brundin P. Triggers, Facilitators, and Aggravators: Redefining Parkinson's Disease Pathogenesis. Trends Neurosci. 2019; 42(1):4-13.

23. Qin XY, Zhang SP, Cao C, Loh YP, Cheng Y. Aberrations in Peripheral Inflammatory Cytokine Levels in Parkinson Disease: A Systematic Review and Meta-analysis. JAMA Neurol. 2016 Nov 1;73(11):1316-1324.

24. Williams-Gray $\mathrm{CH} 1$, Wijeyekoon R1, Yarnall AJ2, Lawson RA2, Breen DP1, Evans JR1, Cummins GA1, Duncan GW3, Khoo TK4, Burn DJ2, Barker RA1; ICICLE-PD study group. Serum immune markers and disease progression in an 
incident Parkinson's disease cohort (ICICLE-PD). Mov Disord. 2016 Jul;31(7):995-1003.

25. Blum-Degen, D., Muller, T., Kuhn, W., Gerlach, M., Przuntek, H., and Riederer, P. (1995) Interleukin-1 beta and interleukin-6 are elevated in the cerebrospinal fluid of Alzheimer's and de novo Parkinson's disease patients. Neurosci Lett $202,17-20$

26. Mogi, M., Harada, M., Narabayashi, H., Inagaki, H., Minami, M., and Nagatsu, T. (1996) Interleukin (IL)-1 beta, IL-2, IL-4, IL-6 and transforming growth factoralpha levels are elevated in ventricular cerebrospinal fluid in juvenile parkinsonism and Parkinson's disease. Neurosci Lett 211, 13-16

27. Mogi, M., Harada, M., Kondo, T., Narabayashi, H., Riederer, P., and Nagatsu, T. (1995) Transforming growth factor-beta 1 levels are elevated in the striatum and in ventricular cerebrospinal fluid in Parkinson's disease. Neurosci Lett 193, 129132

28. Lindqvist, D., Hall, S., Surova, Y., Nielsen, H. M., Janelidze, S., Brundin, L., and Hansson, O. (2013) Cerebrospinal fluid inflammatory markers in Parkinson's disease--associations with depression, fatigue, and cognitive impairment. Brain Behav Immun 33, 183-189

29. Gardai SJ, Mao W, Schüle B, Babcock M, Schoebel S, Lorenzana C, Alexander J, Kim S, Glick H, Hilton K, Fitzgerald JK, Buttini M, Chiou SS, McConlogue L, Anderson JP, Schenk DB, Bard F, Langston JW, Yednock T, Johnston JA. Elevated alpha-synuclein impairs innate immune cell function and provides a 
potential peripheral biomarker for Parkinson's disease. PLoS One. 2013 Aug 23;8(8):e71634.

30. Chahine LM, Qiang J, Ashbridge E, Minger J, Yearout D, Horn S, Colcher A, Hurtig HI, Lee VM, Van Deerlin VM, Leverenz JB, Siderowf AD, Trojanowski JQ, Zabetian CP, Chen-Plotkin A. Clinical and biochemical differences in patients having Parkinson disease with vs without GBA mutations. JAMA Neurol. 2013 Jul;70(7):852-8.

31. Grozdanov V, Bliederhaeuser C, Ruf WP, Roth V, Fundel-Clemens K, Zondler L, Brenner D, Martin-Villalba A, Hengerer B, Kassubek J, Ludolph AC, Weishaupt $\mathrm{JH}$, Danzer KM. Inflammatory dysregulation of blood monocytes in Parkinson's disease patients. Acta Neuropathol. 2014 Nov;128(5):651-63.

32. Saunders JA, Estes KA, Kosloski LM, Allen HE, Dempsey KM, Torres-Russotto DR, Meza JL, Santamaria PM, Bertoni JM, Murman DL, Ali HH, Standaert DG, Mosley RL, Gendelman HE. CD4+ regulatory and effector/memory T cell subsets profile motor dysfunction in Parkinson's disease. J Neuroimmune Pharmacol. 2012 Dec;7(4):927-38.

33. Sulzer D, Alcalay RN, Garretti F, Cote L, Kanter E, Agin-Liebes J, Liong C, McMurtrey C, Hildebrand WH, Mao X, Dawson VL, Dawson TM, Oseroff C, Pham J, Sidney J, Dillon MB, Carpenter C, Weiskopf D, Phillips E, Mallal S, Peters B, Frazier A, Lindestam Arlehamn CS, Sette A. T cells from patients with Parkinson's disease recognize $\alpha$-synuclein peptides. Nature. 2017 Jun 29;546(7660):656-661 . 
34. Lindestam Arlehamn CS, Dhanwani R, Pham J, Kuan R, Frazier A, Rezende Dutra J , Phillips E, Mallal S, Roederer M, Marder KS, Amara AW, Standaert DG, Goldman JG, Litvan I, Peters B, Sulzer D, Sette A. a-Synuclein-specific T cell reactivity is associated with preclinical and early Parkinson's disease. Nature Comm. 2020, in press.

35. Bartels AL, Willemsen AT, Doorduin J, de Vries EF, Dierckx RA, Leenders KL. [11C]-PK11195 PET: quantification of neuroinflammation and a monitor of antiinflammatory treatment in Parkinson's disease? Parkinsonism Relat Disord. 2010 Jan;16(1):57-9.

36. Ghadery C, Koshimori Y, Coakeley S, Harris M, Rusjan P, Kim J, Houle S, Strafella AP. Microglial activation in Parkinson's disease using [18F]-FEPPA. J Neuroinflammation. 2017 Jan 11;14(1):8.

37. Horti AG, Naik R, Foss CA, Minn I, Misheneva V, Du Y, Wang Y, Mathews WB, Wu Y, Hall A, LaCourse C, Ahn HH, Nam H, Lesniak WG, Valentine H, Pletnikova O, Troncoso JC, Smith MD, Calabresi PA, Savonenko AV, Dannals RF, Pletnikov MV, Pomper MG. PET imaging of microglia by targeting macrophage colony-stimulating factor 1 receptor (CSF1R). Proc Natl Acad Sci U S A. $2019 ; 116(5): 1686-1691$.

38. Lema Tomé CM, Tyson T, Rey NL, Grathwohl S, Britschgi M, Brundin P. Inflammation and $\alpha$-synuclein's prion-like behavior in Parkinson's disease--is there a link? Mol Neurobiol. 2013; 47(2):561-74

39. Seok J, Warren HS, Cuenca AG, Mindrinos MN, Baker HV, Xu W, Richards DR, McDonald-Smith GP, Gao H, Hennessy L, Finnerty CC, López CM, Honari S, 
Moore EE, Minei JP, Cuschieri J, Bankey PE, Johnson JL, Sperry J, Nathens AB, Billiar TR, West MA, Jeschke MG, Klein MB, Gamelli RL, Gibran NS, Brownstein BH, Miller-Graziano C, Calvano SE, Mason PH, Cobb JP, Rahme LG, Lowry SF, Maier RV, Moldawer LL, Herndon DN, Davis RW, Xiao W, Tompkins RG; Inflammation and Host Response to Injury, Large Scale Collaborative Research Program. Genomic responses in mouse models poorly mimic human inflammatory diseases. Proc Natl Acad Sci U S A. 2013 Feb 26;110(9):3507-12.

40. Carvey PM, Chang Q, Lipton JW, Ling Z. Prenatal exposure to the bacteriotoxin lipopolysaccharide leads to long-term losses of dopamine neurons in offspring: a potential, new model of Parkinson's disease. Front Biosci. 2003 Sep 1;8:s826-37

41. Ling Z, Chang QA, Tong CW, Leurgans SE, Lipton JW, Carvey PM. Rotenone potentiates dopamine neuron loss in animals exposed to lipopolysaccharide prenatally. Exp Neurol. 2004 Dec;190(2):373-83.

42. Zhu Y, Carvey PM, Ling Z. Altered glutathione homeostasis in animals prenatally exposed to lipopolysaccharide. Neurochem Int. 2007 Mar;50(4):671-80.

43. Gomez-Nicola D, Perry VH. Microglial dynamics and role in the healthy and diseased brain: a paradigm of functional plasticity. Neuroscientist. 2015 Apr;21(2):169-84

44. Raval AP, Martinez CC, Mejias NH, de Rivero Vaccari JP. Sexual dimorphism in inflammasome-containing extracellular vesicles and the regulation of innate immunity in the brain of reproductive senescent females. Neurochem Int. 2018 Nov 27. pii: S0197-0186(18)30536-9 
45. Williams-Gray CH, Wijeyekoon RS, Scott KM, Hayat S, Barker RA, Jones JL. Abnormalities of age-related T cell senescence in Parkinson's disease. J Neuroinflammation. 2018;15:166.

46. Ros-Bernal F, Hunot S, Herrero MT, Parnadeau S, Corvol JC, Lu L, AlvarezFischer D, Carrillo-de Sauvage MA, Saurini F, Coussieu C, Kinugawa K, Prigent A, Höglinger G, Hamon M, Tronche F, Hirsch EC, Vyas S. Microglial glucocorticoid receptors play a pivotal role in regulating dopaminergic neurodegeneration in parkinsonism. Proc Natl Acad Sci U S A. 2011; 108:66327.

47. Zecca L, Wilms H, Geick S, Claasen JH, Brandenburg LO, Holzknecht C, Panizza ML, Zucca FA, Deuschl G, Sievers J, Lucius R. Human neuromelanin induces neuroinflammation and neurodegeneration in the rat substantia nigra: implications for Parkinson's disease. Acta Neuropathol. 2008; 116:47-55.

48. Noelker C, Morel L, Osterloh A, Alvarez-Fischer D, Lescot T, Breloer M, Gold M, Oertel WH, Henze C, Michel PP, Dodel RC, Lu L, Hirsch EC, Hunot S, Hartmann A. Heat shock protein 60: an endogenous inducer of dopaminergic cell death in Parkinson disease. J Neuroinflammation. 2014 May 8;11:86. doi: 10.1186/1742-2094-11-86.

49. Noelker C, Morel L, Lescot T, Osterloh A, Alvarez-Fischer D, Breloer M, Henze C, Depboylu C, Skrzydelski D, Michel PP, Dodel RC, Lu L, Hirsch EC, Hunot S, Hartmann A. Toll like receptor 4 mediates cell death in a mouse MPTP model of Parkinson disease. Sci Rep. 2013;3:1393. doi: 10.1038/srep01393. 
50. Su X, Maguire-Zeiss KA, Giuliano R, Prifti L, Venkatesh K, Federoff HJ. Synuclein activates microglia in a model of Parkinson's disease. Neurobiol Aging. 2008; 29(11):1690-701.

51. Harms AS, Cao S, Rowse AL, Thome AD, Li X, Mangieri LR, Cron RQ, Shacka JJ, Raman C, Standaert DG. MHCII is required for $\alpha$-synuclein-induced activation of microglia, CD4 T cell proliferation, and dopaminergic neurodegeneration. J Neurosci. 2013 Jun 5;33(23):9592-600

52. Reynolds AD, Glanzer JG, Kadiu I, Ricardo-Dukelow M, Chaudhuri A, Ciborowski P, Cerny R, Gelman B, Thomas MP, Mosley RL, Gendelman HE. Nitrated alpha- synuclein-activated microglial profiling for Parkinson's disease. J Neurochem. 2008; 104:1504-25.

53. Reynolds AD, Stone DK, Mosley RL, Gendelman HE. Nitrated a-synucleininduced alterations in microglial immunity are regulated by CD4+ T cell subsets. J Immunol. 2009; 182:4137-49.

54. Benner EJ, Banerjee R, Reynolds AD, Sherman S, Pisarev VM, Tsiperson V, Nemachek C, Ciborowski P, Przedborski S, Mosley RL, Gendelman HE. Nitrated alpha-synuclein immunity accelerates degeneration of nigral dopaminergic neurons. PLoS One. 2008 Jan 2;3(1):e1376.

55. Sampson TR, Debelius JW, Thron T, Janssen S, Shastri GG, Ilhan ZE, Challis C, Schretter CE, Rocha S, Gradinaru V, Chesselet MF, Keshavarzian A, Shannon KM, Krajmalnik-Brown R, Wittung-Stafshede P, Knight R, Mazmanian SK. Gut Microbiota Regulate Motor Deficits and Neuroinflammation in a Model of Parkinson's Disease. Cell. 2016 Dec 1;167(6):1469-1480 
56. Pereira PAB, Aho VTE, Paulin L, Pekkonen E, Auvinen P, Scheperjans F. Oral and nasal microbiota in Parkinson's disease. Parkinsonism Relat Disord. 2017 May;38:61-67

57. Bliederhaeuser C, Grozdanov V, Speidel A, Zondler L, Ruf WP, Bayer H, Kiechle M, Feiler MS, Freischmidt A, Brenner D, Witting A, Hengerer B, Fändrich M, Ludolph AC, Weishaupt JH, Gillardon F, Danzer KM. Acta Neuropathol. 2016 Mar;131(3):379-91.

58. Parillaud VR, Lornet G, Monnet Y, Privat A-L, Haddad AT, Brochard V, Bekaert A, Baudesson de Chanville C, Hirsch EC, Combadière C, Hunot S, Lobsiger CS. Analysis of monocyte infiltration in MPTP mice reveals that microglial CX3CR1 protects against neurotoxic over-induction of monocyte-attracting CCL2 by astrocytes. J Neuroinflammation. 2017; 14: 60

59. Calabrese V, Santoro A, Monti D, Crupi R, Di Paola R, Latteri S, Cuzzocrea S, Zappia M, Giordano J, Calabrese EJ, Franceschi C. Aging and Parkinson's Disease: Inflammaging, neuroinflammation and biological remodeling as key factors in pathogenesis. Free Radic Biol Med. 2018 Feb 1;115:80-91

60. Prinz M, Priller J, Sisodia SS, Ransohoff RM. Heterogeneity of CNS myeloid cells and their roles in neurodegeneration. Nat Neurosci. 2011 Sep 27;14(10):1227-35.

61. Kierdorf K, Masuda T, Jordão MJC, Prinz M, Macrophages at CNS interfaces: ontogeny and function in health and disease. Nat Rev Neurosci. 2019 Sep;20(9):547-562. 
62. Wu DC, Jackson-Lewis V, Vila M, Tieu K, Teismann P, Vadseth C, Choi DK, Ischiropoulos $\mathrm{H}$, Przedborski S. Blockade of microglial activation is neuroprotective in the 1-methyl-4-phenyl-1,2,3,6-tetrahydropyridine mouse model of Parkinson disease. J Neurosci. 2002 Mar 1;22(5):1763-71.

63. Breidert T, Callebert J, Heneka MT, Landreth G, Launay JM, Hirsch EC. Protective action of the peroxisome proliferator-activated receptor-gamma agonist pioglitazone in a mouse model of Parkinson's disease. J Neurochem. 2002 Aug;82(3):615-24.

64. McGeer PL, Schwab C, Parent A, Doudet D. Presence of reactive microglia in monkey substantia nigra years after 1-methyl-4-phenyl-1,2,3,6tetrahydropyridine administration. Ann Neurol. 2003 Nov;54(5):599-604.

65. Langston JW1, Forno LS, Tetrud J, Reeves AG, Kaplan JA, Karluk D. Evidence of active nerve cell degeneration in the substantia nigra of humans years after 1methyl-4-phenyl-1,2,3,6-tetrahydropyridine exposure. Ann Neurol. 1999 Oct;46(4):598-605.

66.

67. Harms AS, Thome AD, Yan Z, Schonhoff AM, Williams GP, Li X, Liu Y, Qin H, Benveniste EN, Standaert DG. Peripheral monocyte entry is required for alphaSynuclein induced inflammation and Neurodegeneration in a model of Parkinson disease. Exp Neurol. 2018 Feb;300:179-187.

68. Sommer A, Marxreiter F, Krach F, Fadler T, Grosch J, Maroni M, Graef D, Eberhardt E, Riemenschneider MJ, Yeo GW, Kohl Z, Xiang W, Gage FH, Winkler J, Prots I, Winner B. Th17 Lymphocytes Induce Neuronal Cell Death in a 
Human iPSC-Based Model of Parkinson's Disease. Cell Stem Cell. 2018;23(1):123-131

69. Rasmussen MK, Mestre H, Nedergaard M. The glymphatic pathway in neurological disorders. Lancet Neurol. 2018; 17(11):1016-1024.

70. Valdinocci D, Radford RA, Siow SM, Chung RS, Pountney DL. Potential Modes of Intercellular a-Synuclein Transmission. Int J Mol Sci. 2017 Feb 22;18(2).

71. Kortekaas R, Leenders KL, van Oostrom JC, Vaalburg W, Bart J, Willemsen AT, Hendrikse $\mathrm{NH}$. Blood-brain barrier dysfunction in parkinsonian midbrain in vivo. Ann Neurol. 2005 Feb;57(2):176-9.

72. Faucheux BA, Bonnet AM, Agid Y, Hirsch EC. Blood vessels change in the mesencephalon of patients with Parkinson's disease. Lancet. 1999 Mar 20;353(9157):981-2 .

73. Barcia C, Bautista V, Sánchez-Bahillo A, Fernández-Villalba E, Faucheux B, Poza y Poza M, Fernandez Barreiro A, Hirsch EC, Herrero MT. Changes in vascularization in substantia nigra pars compacta of monkeys rendered parkinsonian. J Neural Transm (Vienna). 2005;112(9):1237-48.

74. Janelidze S, Lindqvist D, Francardo V, Hall S, Zetterberg H, Blennow K, Adler CH, Beach TG, Serrano GE, van Westen D, Londos E, Cenci MA, Hansson O. Increased CSF biomarkers of angiogenesis in Parkinson disease. Neurology. 2015 Nov 24;85(21):1834-42.

75. Ohlin KE, Sebastianutto I, Adkins CE, Lundblad C, Lockman PR, Cenci MA. Impact of L-DOPA treatment on regional cerebral blood flow and metabolism in 
the basal ganglia in a rat model of Parkinson's disease. Neuroimage. 2012 May 15;61(1):228-39.

76. Mondello S, Kobeissy F, Mechref Y, Zhao J, Talih FR, Cosentino F, Antelmi E, Moresco M, Plazzi G, Ferri R. Novel biomarker signatures for idiopathic REM sleep behavior disorder: A proteomic and system biology approach. Neurology. 2018 Oct 30;91(18):e1710-e1715.

77. Kim R, Jun JS, Kim HJ, Jung KY, Shin YW, Yang TW, Kim KT, Kim TJ, Byun Jl, Sunwoo JS, Jeon B. Peripheral Blood Inflammatory Cytokines in Idiopathic REM Sleep Behavior Disorder. Mov Disord. 2019 Nov;34(11):1739-1744.

78. King E, O'Brien J, Donaghy P, Williams-Gray CH, Lawson RA, Morris CM, Barnett N, Olsen K, Martin-Ruiz C, Burn D, Yarnall AJ, Taylor JP, Duncan G, Khoo TK, Thomas A. Inflammation in mild cognitive impairment due to Parkinson's disease, Lewy body disease, and Alzheimer's disease. Int J Geriatr Psychiatry. 2019 Aug;34(8):1244-1250.

79. Stokholm MG, Iranzo A, Østergaard K, Serradell M, Otto M, Svendsen KB, Garrido A, Vilas D, Borghammer P, Santamaria J, Møller A, Gaig C, Brooks DJ, Tolosa E, Pavese N. Assessment of neuroinflammation in patients with idiopathic rapid-eye-movement sleep behaviour disorder: a case-control study. Lancet Neurol. 2017 Oct;16(10):789-796.

80. Gao X, Chen H, Schwarzschild MA, Ascherio A. Use of ibuprofen and risk of Parkinson disease. Neurology. 2011; 76:863-9. 
81. Gagne JJ, Power MC. Anti-inflammatory drugs and risk of Parkinson disease: a meta-analysis. Neurology. 2010 Mar 23;74(12):995-1002.

82. Samii A, Etminan M, Wiens MO, Jafari S. NSAID use and the risk of Parkinson's disease: systematic review and meta-analysis of observational studies. Drugs Aging. 2009;26(9):769-79.

83. Ren L, Yi J, Yang J, Li P, Cheng X, Mao P. Nonsteroidal anti-inflammatory drugs use and risk of Parkinson disease: A dose-response meta-analysis. Medicine (Baltimore). 2018 Sep;97(37):e12172.

84. NINDS NET-PD Investigators. A randomized, double-blind, futility clinical trial of creatine and minocycline in early Parkinson disease. Neurology. 2006 Mar 14;66(5):664-71.

85. Peter I, Dubinsky M, Bressman S, Park A, Lu C, Chen N, Wang A. Anti-Tumor Necrosis Factor Therapy and Incidence of Parkinson Disease Among Patients With Inflammatory Bowel Disease. JAMA Neurol. 2018 Aug 1;75(8):939-946.

86. Schonhoff AM, Williams GP, Wallen ZD, Standaert DG, Harms AS. Innate and adaptive immune responses in Parkinson's disease. Progress in Brain Research, 2020, in press.

87. Parkinson, J. An essay on the shaking palsy. Sherwood, Neely, and Jones, Paternoster Row, London, 1817. 


\section{Acknowledgements}

This work was inspired by a conference hosted by Wiley Publishing in Hoboken, New Jersey, USA in June, 2019. The authors thank the other attendees for their thoughtful input.

\section{Documentation of Author Roles}

Manuscript Preparation:
A. Writing of the first draft: Etienne Hirsch
B. Review and Critique; Etienne Hirsch and David Standaert

\section{Full financial disclosure for the previous 12 months:}

Dr. Standaert is a member of the faculty of the University of Alabama at Birmingham and is supported by endowment and University funds. Dr. Standaert is an investigator in studies funded by Abbvie, Inc., Avid Radiopharmaceuticals, the American Parkinson Disease Association, the Michael J. Fox Foundation for Parkinson Research, Alabama Department of Commerce, the Department of Defense, and NIH grants P01NS087997, P50NS108675, R25NS079188, P2CHD086851, P30NS047466, and T32NS095775. He has a clinical practice and is compensated for these activities through the University of Alabama Health Services Foundation. In addition, since January 1, 2019 he has served as a consultant for or received honoraria from Axovant Sciences, Inc., Censa Pharmaceuticals, Abbvie Inc., Grey Matter Technologies, Theravance Inc., the Kennedy Krieger Institute, 
McGraw Hill Publishers, Sanofi- Aventis, RTI Consultants, Cerevance Inc., Yale University and Michigan State University.

Dr. Hirsch is a CNRS research director at Insitut du Cerveau et de la moelle épinière, UMR INSERM 1127, CNRS UMR 7225, Sorbonne université UMR1127. He is also the national director of the Neuroscience, cognitive sciences, neurology and psychiatry at Inserm and Aviesan. EH acknowledges the financial support from CNRS, INSERM, ICM, Sorbonne Université and from the program "Investissements d'avenir" ANR-10-IAIHU-06. 